\title{
Métodos para cuantificar y monitorear el sobrediagnóstico en el rastreo de cáncer
}

\author{
Methods to quantify and monitor overdiagnosis in cancer screening
}

\section{Objetivo}

Determinar el método óptimo para cuantificar y monitorear en el tiempo, el sobrediagnóstico generado por la pesquisa de cáncer.

\section{Fuentes de datos, selección de los estudios y extracción de los datos}

PubMed y EMBASE hasta febrero de 2014 y búsqueda manual de estudios en idioma inglés de cualquier diseño, que hubieran cuantificado el sobrediagnóstico de nueve cánceres: próstata, mama, pulmón, colon y recto, melanoma, vejiga, riñón, tiroides y útero. Fueron excluidas las series de casos, los
Carter J L, y col. BMJ. 2015;350:g7773 reportes de casos y las revisiones que solamente hubieran reportado resultados de estudios.Los datos fueron extraídos independientemente por dos revisores, y las discrepancias resueltas por consenso. Fueron considerados resultados de interés el método usado para medir el sobrediagnóstico, y las ventajas y desventajas de cada método para: 1) estimar la magnitud y la precisión de la frecuencia de sobrediagnóstico; 2) monitorear en el tiempo el sobrediagnóstico.

\section{Resultados principales}

Se detallan en la tabla1.

Tabla 1. fortalezas y debilidades de los principales diseños de investigación clínica para medir sobrediagnóstico.

\begin{tabular}{|c|c|c|}
\hline $\begin{array}{l}\text { Diseño/ } \\
\text { Confianza en los } \\
\text { resultados }\end{array}$ & Fortalezas & Debilidades \\
\hline $\begin{array}{l}\text { Seguimiento estudios aleatorizados/ } \\
\text { MODERADA }\end{array}$ & $\begin{array}{l}\text { Permiten controlar sesgos. } \\
\text { Responden la pregunta de interés de manera directa. }\end{array}$ & $\begin{array}{l}\text { Consumen mucho tiempo y recursos. } \\
\text { Tienen una limitada validez externa. } \\
\text { No son útiles para monitorear. }\end{array}$ \\
\hline $\begin{array}{l}\text { Modelos } \\
\text { Matemáticos/ } \\
\text { BAJA }\end{array}$ & $\begin{array}{l}\text { Evalúan distintos escenarios al mismo tiempo. } \\
\text { Pueden explorar escenarios no evaluados en la } \\
\text { práctica. } \\
\text { No tienen límites de tiempo y pueden ser útiles para } \\
\text { monitorear. }\end{array}$ & $\begin{array}{l}\text { La validez depende de las presunciones (indirectos). } \\
\text { Hay necesidad de actualización permanente de los datos. } \\
\text { Los resultados varían sensiblemente según las presunciones. } \\
\text { Dan una falsa sensación de precisión. } \\
\text { Es difícil evaluar la confianza de sus resultados. }\end{array}$ \\
\hline $\begin{array}{l}\text { Estudios patológicos y de imágenes/ } \\
\text { BAJA }\end{array}$ & Son sencillos y permiten monitoreo & $\begin{array}{l}\text { La validez depende de las presunciones (indirectos). } \\
\text { Hay necesidad de certeza en el diagnóstico y de cómo fue realizado. } \\
\text { No toman en cuenta la mortalidad por otras causas. }\end{array}$ \\
\hline $\begin{array}{l}\text { Ecológicos y de cohorte/ } \\
\text { BAJA }\end{array}$ & $\begin{array}{l}\text { Responden la pregunta de interés de manera directa, } \\
\text { en distintos escenarios de la realidad. } \\
\text { Permiten el monitoreo }\end{array}$ & $\begin{array}{l}\text { Existe potencial presencia de confundidores entre poblaciones } \\
\text { Dependen de la calidad de los registros de enfermedad y de sus confundidores. } \\
\text { Requieren un moderado tiempo de seguimiento. }\end{array}$ \\
\hline
\end{tabular}

\section{Conclusiones}

Esta revisión sistemática destaca la alta probabilidad de sesgo en los diseños basados en modelos o en los que procuran cuantificar el sobrediagnóstico usando características patológicas o de imágenes.
Conflictos de interés: No presenta. Fuente de financiamiento: Agency for Healthcare Research and Quality. USA

\section{Comentario}

Entre las debilidades de esta revisión sistemática destacamos haber limitado la búsqueda a publicaciones en inglés. Sin embargo, su lectura nos pone ante el hecho que, los distintos diseños utilizados, estiman la magnitud del sobrediagnóstico en cáncer de manera inconsistente. Vale destacar que ninguno de estos diseños, que se complementarían en sus debilidades y fortalezas, puede negar la existencia de esta realidad, definida con este término vago, desafío para pacientes, médicos e investigadores.

\section{Conclusiones del revisor}

Parece atinado focalizar nuestros esfuerzos en la solicitud de estudios preventivos respaldados por evidencia proveniente de ensayos aleatorizados, tal como lo exige el compromiso médico con las personas sanas: primero no dañar.

De más está decir que el sobrediagnóstico continuará hasta que tanto los profesionales de la salud como los pacientes y la sociedad en su conjunto aceptemos que la incertidumbre inherente a la práctica médica'.

Hugo Catalano [ Profesor adjunto Medicina Interna. Facultad de Medicina. UBA hcatalano@ fibertel.com.ar ]

Catalano H. Métodos para cuantificar y monitorear el sobrediagnóstico en el rastreo de cáncer. Evid Act Pract Ambul. 2016;19(1):22. Ene-Mar. Comentado de: Carter JL. y col. Quantifying and monitoring overdiagnosis in cancer screening: a systematic review of methods. BMJ. 2015;350:g7773. PMID: 25569206.

Referencias

1. Hoffman J. Intolerance of error and culture of blame drive medical excess. BMJ 2014;349:g5702 